II Congresso Brasileiro de

Fluidodinâmica Computacional

27 a 29 de Junho de 2018

Rio de Janeiro, RJ

\title{
ESTUDO DO ACOPLAMENTO DAS EQUAÇÕES DE BALANÇO POPULACIONAL À ABORDAGEM EULE- RIANA-EULERIANA NA SIMULAÇÃO DE UM LEITO FLUIDIZADO CIRCULANTE
}

\author{
F. Q. MENDES ${ }^{1}$ E D. NORILER ${ }^{1}$ \\ ${ }^{1}$ Universidade Estadual de Campinas, Faculdade de Engenharia Química \\ Email para contato: felipe.q.mendes@gmail.com / dnoriler@feq.unicamp.br \\ RESUMO - A abordagem Euleriana-Euleriana acoplada às equações de balanço \\ populacional foi utilizada para modelar os escoamento gás-sólido em um leito \\ fluidizado circulante com o intuito de avaliar os efeitos da distribuição do ta- \\ manho de partícula no escoamento. O método de quadratura direta baseada em \\ momentos com dois pontos de quadratura foi utilizado para solução das equações \\ de balanço populacional. Os resultados mostram uma segregação das partículas \\ com as maiores concentradas preferencialmente na base do leito ao passo que \\ as menores tendem deixar o leito pelo topo. No entanto, observou-se pouca \\ influência desta distribuição sobre o perfil fluidodinâmico médio no leito.
}

\section{INTRODUÇÃO}

Leito fluidizado circulante (CFB) tem sido muito utilizado nas indústrias químicas, metalúrgicas e para geração de energia. Devido ao grande gasto de tempo e dinheiro em estudos experimentais, esses têm sido complementados por estudos numéricos utilizando a fluidodinâmica computacional.

Ademais, escoamentos em CFB são multifásicos, sendo normalmente uma fase gasosa e uma fase particulada. Tradicionalmente, a fase particulada é modelada apenas utilizando o diâmetro médio de partícula. Entretanto, em situações reais, a fase sólida é caracterizada por uma distribuição de tamanho de partícula (PSD) e isso pode causar um grande impacto no escoamento. Atualmente, alguns trabalhos utilizam uma abordagem Euleriana-Lagrangiana para implementar a PSD, no entanto, o uso dessa abordagem acarreta em um custo computacional muito grande. Uma alternativa é utilizar uma abordagem Euleriana-Euleriana (EE) em conjunto com as equações de balaço populacional (PBE) como os trabalhos apresentados por Mazzei (2008) e Niemi (2012).

Deste modo, foi proposto o acoplamento das PBE's à abordagem EE com o intuito de avaliar os efeitos da PSD no escoamento em CFB e reconstruir as PSD em diferentes alturas do CFB.

\section{METODOLOGIA}

A métodologia foi separada em modelagem matemática e simulação numérica. 


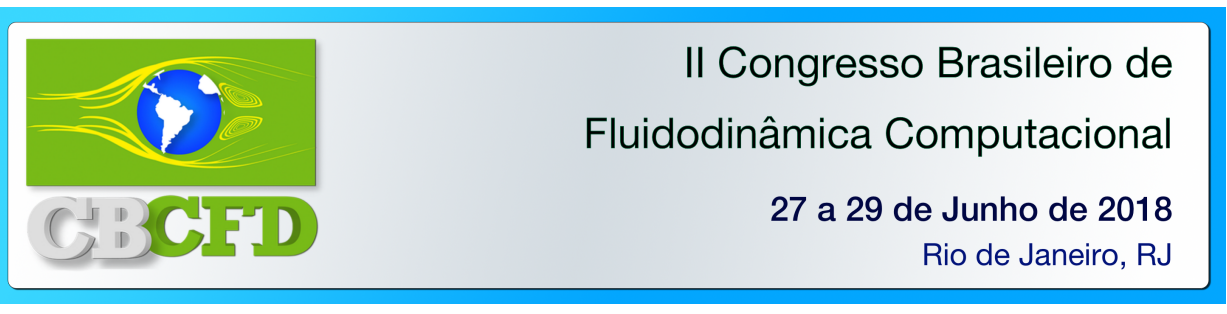

\subsection{Modelagem}

A modelagem foi baseada no trabalho de Niemi (2012), o qual utiliza método de quadratura direta baseada em momentos (DQMOM) com dois pontos de quadratura para resolução das PBE's. O sistema de equações básicas da modelagem é apresentado na Tabela 1.

Tabela 1 - Equações resolvidas neste modelo

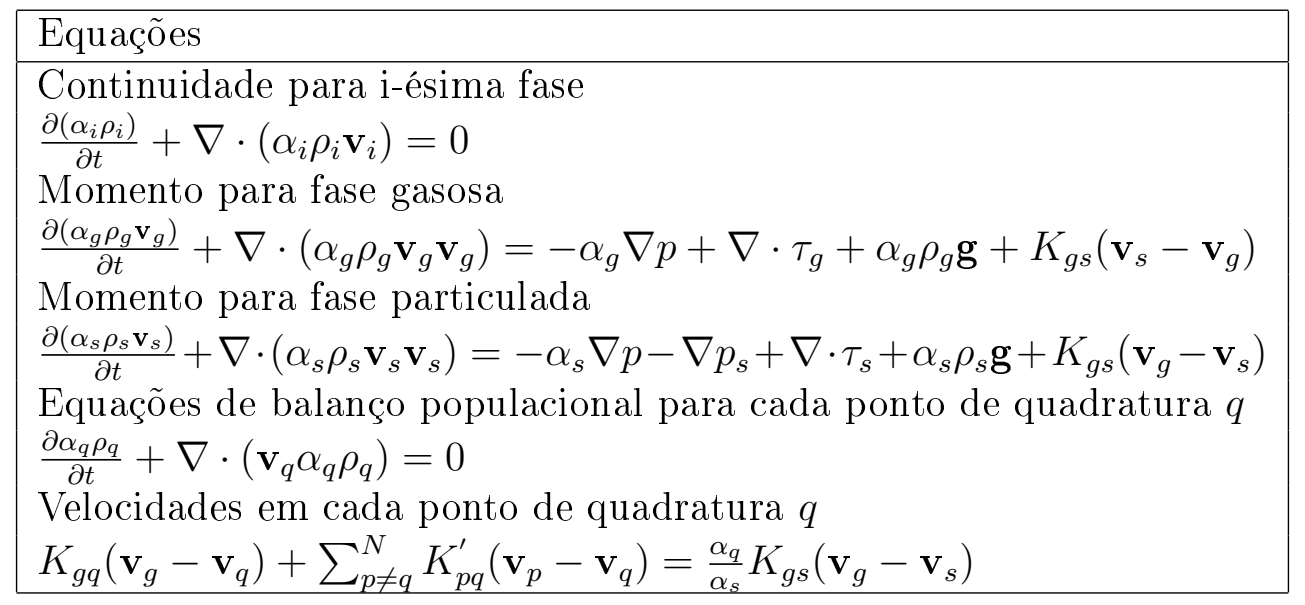

É importante destacar alguns pontos da modelagem. Primeiramente, os termos de pressão e de tensão da fase sólida que aparecem na equação de momento foram calculados utilizando a teoria cinética dos escoamentos granulares (KTGF). Outro ponto é que a equação final para o cálculo das velocidades dos pontos de quadratura foi desenvolvida a partir da formulação de mistura descrita por Manninen et al. (1996). Ainda, os coeficientes de arraste entre a fase particulada e a gasosa e entre os pontos de quadratura e a fase gasosa foram calculados seguindo o modelo de Gidaspow (1994). O coeficiente de arraste entre os pontos de quadratura foi calculado segundo o modelo proposto por Syamlal (1987). Por fim, o modelo de turbulência usado foi o $k-\varepsilon$ disperso.

\subsection{Simulação}

Para realização deste estudo foi criada uma geometria no software ICEM 17.2 baseada na utilizada por Niemi (2012). A malha hexaédrica gerada utilizando o ICEM 17.2 é composta por hexaedros de $5 \mathrm{~mm}$ de lado totalizando 48800 células. A simulação foi realizada no software FLUENT 17.2 para fração volumétrica de 0.78 para o ponto de quadratura de $255 \mu \mathrm{m}$ e 0.22 para a de $416 \mu \mathrm{m}$ de modo que o diâmetro médio de Sauter é $279 \mu \mathrm{m}$ e as condições de contorno foram utilizadas as mesmas de Niemi (2012).

\section{RESULTADOS E DISCUSSÃO}

A fração volumétrica está relacionada com o peso de cada ponto de quadratura, dessa forma, as PBE foram resolvidas para a fração volumétrica e os resultados da simulação 


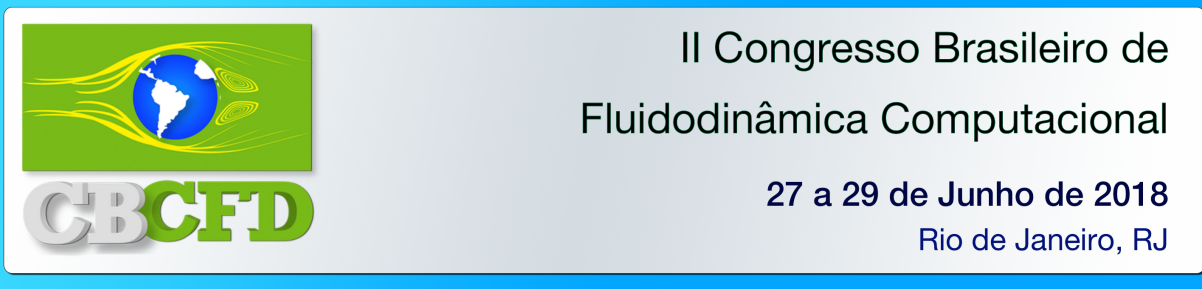

obtidos para fração volumétrica média num tempo de 60 s estão representados na Figura 1. Pôde-se verificar que para o ponto de quadratura de maior abcissa $(416 \mu m)$ a fração volumétrica ficou mais concentrada na parte inferior do leito, enquanto que para a menor abcissa $(255 \mu \mathrm{m})$ a fração volumétrica se encontra mais homogênea ao longo da altura do leito. No entanto, apesar das diferenças entres os dois pontos de quadraturas, o total somando esses pontos não divergiu muito do valor obtido para as frações volumétricas médias pela simulação com o diâmetro médio de $279 \mu \mathrm{m}$.

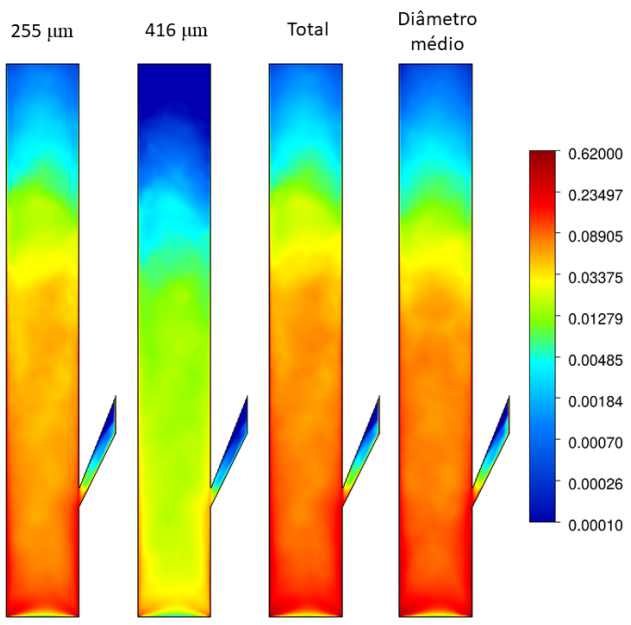

Figura 1 - Perfil da fração volumétrica média para os pontos de quadratura, o total somando os dois pontos de quadratura e o diâmetro médio de Sauter inicial.

Utilizando a fração volumétrica foi possível calcular os pesos de cada ponto de quadratura e, assim, calcular os momentos de ordem 0, 1, 2 e 3. Por definição, o diâmetro médio de Sauter é calculado pela divisão do momento de ordem 3 pelo momento de ordem 2. Deste modo foi possível calcular o diâmetro médio de Sauter ao longo do leito e ainda calcular a média desse diâmetro em cada altura do leito como mostrado na Figura 2. Ainda de posse dos momentos de ordem 0, 1 e 2, pôde-se calcular os parâmetros de uma distribuição log-normal de modo a reconstruir as PSD's nas alturas de 2, 2,5 e 2,98 m. As curvas estão representadas na Figura 2.

Observando a Figura 2, percebe-se que muito próximo ao fundo do leito o diâmetro médio de Sauter foi maior que o diâmetro médio inicial e que acima da altura de dois metros do leito ele começou a ficar menor, evidenciando assim uma segregação das partículas no leito. Desta forma, abaixo da altura de dois metros as curvas de distribuição reconstruídas eram quase idênticas, já acima dessa altura nota-se que há uma diminuição da amplitude da distribuição e o aumento do pico próximo ao valor da menor abcissa.

\section{CONCLUSÃO}

Por meio do que foi exposto, ficou evidenciado que o acoplamento das equações de balanço populacional à abordagem Euleriana-Euleriana proporcionou uma segregação das partículas, com as maiores ocupando preferencialmente o fundo do leito enquanto que as 

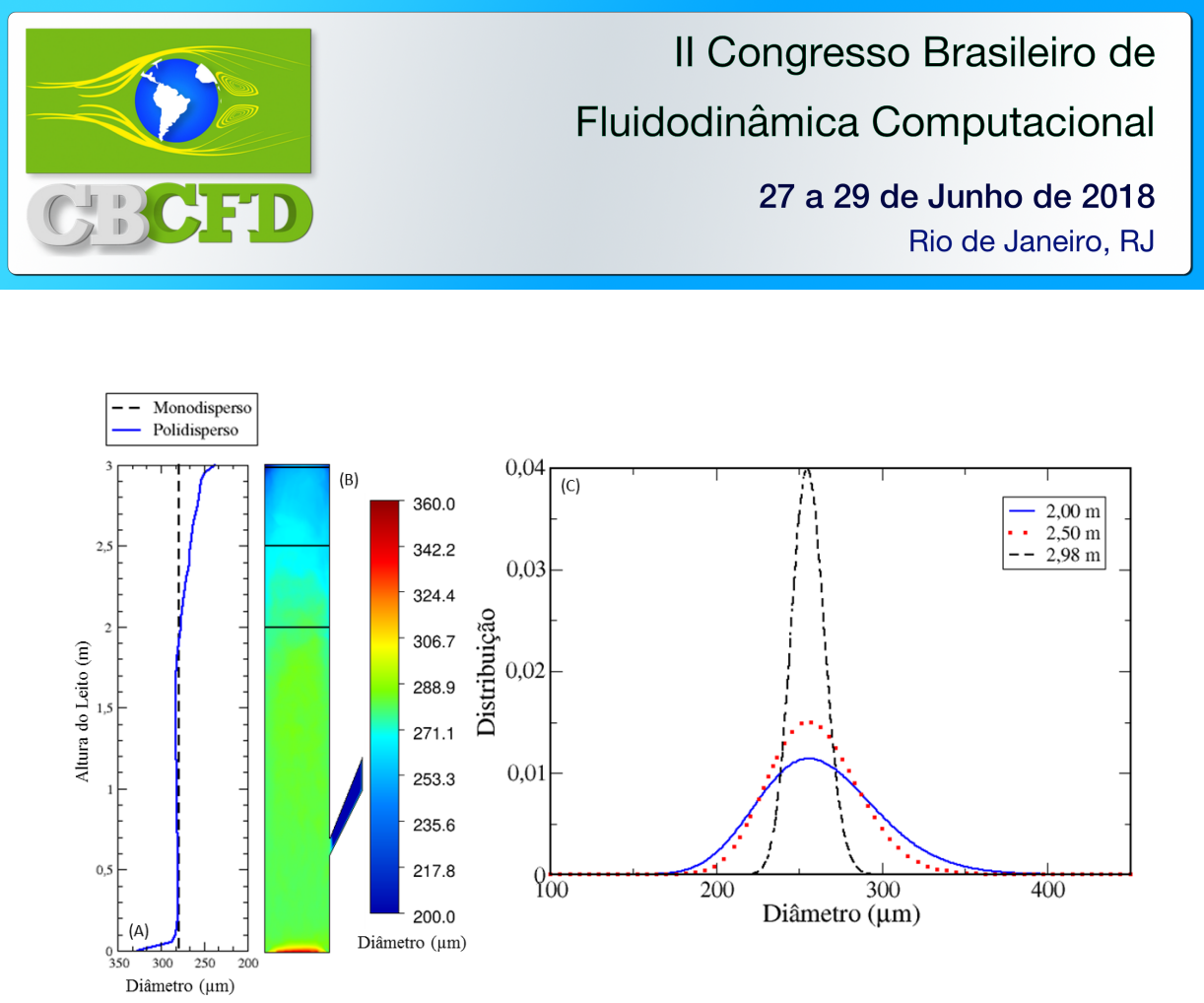

Figura 2 - Relação entre diâmetro médio de Sauter, a posição no leito e a curva de distribuição de tamanho. (A) Curva do diâmetro médio ao logo da altura do leito; (B) Perfil do diâmetro médio no leito fluidizado circulante; (C) Reconstrução das distribuições do tamanho de partícula em determinadas alturas do leito.

menores tendem a deixar o leito na parte superior. Contudo, notou-se que a distribuição do tamanho de partícula teve pouco efeito sobre o perfil fluidodinâmico médio no leito. Futuramente, pretende-se comparar o comportamento do leito utilizando diferentes pontos de quadratura para resolução das equações de balanço populacional.

\section{AGRADECIMENTO}

Os autores agradecem ao Conselho Nacional de Desenvolvimento Científico e Tecnológico (CNPq) pelo auxílio financeiro (Número do processo: 132481/2017-0).

\section{REFERÊNCIAS}

GIDAsPow, D. Multiphase flow and fluidization: continuum and kinetic theory descriptions. Academic press, San Diego, 1994.

Manninen, M.; Taivassalo, V.; Kallio, S. On the mixture model for multiphase flow. VTT Publications 288, Technical Research Centre of Finland Finland, 1996.

MAZZEI, L. Eulerian modelling and computational fluid dynamics simulation of mono and polydisperse fluidized suspensions. Tese de Doutorado, University College London, Department of Chemical Engineering, Londres, UK, 2008.

NiEmi, T. Particle size distribution in cfd simulation of gas-particle flows. Dissertação de Mestrado, Aalto University, School of Science, Aalto, FI, 2012.

Syamlal, M. The particle-particle drag term in a multiparticle model of fluidization. Relatório técnico, National Technical Information Service, Springfield, VA, 1987. 